\title{
PERCEPTIONS OF GENDER ISSUES IN AGRICULTURAL RESOURCE MANAGEMENT AMONG RURAL DWELLERS IN BENUE STATE, NIGERIA
}

\author{
Ejembi, S.A ${ }^{*}$., Obekpa, H.O²., Ivande, P.D ${ }^{3}$ \\ 1 Department of Agricultural Extension and Communication, University of Agriculture, \\ Makurdi, Nigeria. \\ ${ }^{2}$ Department of Agricultural Economics, University of Agriculture, Makurdi, Nigeria. \\ ${ }^{3}$ Department of Home Science, University of Agriculture, Makurdi, Nigeria. \\ *Corresponding author: E-mail: amesimon72@gmail.com
}

Citation: Ejembi, S.A., Obekpa, H.O., Ivande, P.D., 2017. Perceptions of Gender Issues in Agricultural Resource Management Among Rural Dwellers in Benue State, Nigeria. J. Asian Rur. Stud. 1(2): 145-151

\begin{abstract}
Rural livelihood in Nigeria depends largely on natural resources (Land, water, forest etc) which are communally owned. The quality of life in the rural areas and the sustainability of the production system are consequences of how well these resources are managed. Management is a social activity which emphasizes efficient allocation of resources for optimum output, therefore any member of the community irrespective of the gender category with the know-how can be charged with the responsibility of resource utilization for better living standard. However, resource management in the study area has been inequitable as there are obvious cases of male domination. This study, consequently, was undertaken to assess the perceptions of gender issues as they affect sustainable agricultural development. A total of 272 respondents were selected through simple random sampling technique. Structured questionnaire to elicit information for this study, Focus Group Discussion (FGD) with one group from each of the communities was also used to compliment the data from the questionnaire. Results show that majority $(83 \%)$ of the people in the study area did not understand the concept of gender and thus interaction in all issues identified and resource allocation were based on the biological attribute (sex) of the people. Majority (88\%) of the respondents identified right to ownership of resources as main gender issues. Forest resource, land, water or rivers and human beings were among the things identified as community resources. It was concluded that the fundamental problem of resource management in the study area was the poor understanding of the concept of gender, consequently, it is suggested that the people should be sensitized well enough about the meaning of gender so that culturally based action in resource allocation can be modified to guarantee equitable and sustainable access to agricultural productive resources.
\end{abstract}

Keywords: Gender; Issues; Rural Dwellers; Resource

\section{Introduction}

Rural livelihoods in Africa depend largely on natural resources. The quality of life of the people and sustainability of production systems depend on how well these resources are managed (Smith and Hada, 1999). In most rural communities in Nigeria including Okpokwu in Benue state, agriculture is the life-wire of the economy with 
women contributing immensely at every stage of agricultural activities (Ejembi et al., 2006). According to International Institute of Rural Reconstruction (IIRR) (1998), women are key farmers, food producers and care givers; women contribute $60-80 \%$ of domestically produced food, provide nearly half the farm labour and shouldered $90 \%$ of the domestic responsibilities in sub-Saharan Africa. This enormous role of women notwithstanding, they are hardly involved in the management of community resources as they are usually discriminated against on the basis of gender differences when benefits of these resources accrue (Smith and Hadad, 1999). The concept of gender is different from sex. Whereas sex refers to the biological differences between men and women, gender is a social construct referring to the social and economic difference of male and female (IIRR, 1998). According to IIRR (1998), the term is used to analyze the roles, responsibilities constraints and opportunities of man and woman in development. The roles men or women play in the society depend on society's expectations rather than on their biological differences. Whereas there a significant local and national peculiarities, roles assigned to men and women are largely culturally predetermined and different. When these roles and some fundamental gender issues are analyzed and understood a premium would be placed on gender equity (IIRR, 1998). Gender analysis is the systematic use of tools to diagnose the differences between women and men regarding their specific activities, conditions, need access to and control over resources, and access to development benefits and decision making. It seeks to examine how power, resources, opportunities and benefits tend to be shared among women and men in the society (IIRR, 1998).

African Development Bank (ADB, 2005), reported that participation rate of men and women folk in public and private spheres is influenced largely by the cultural environments. Indeed culture has been invoked to legitimize unequal relations in a manner that to a large extent favours male gender. This situation has not facilitated rural development.

Today, various governments are laying emphasis on rural development through rural people empowerment to guarantee food security. Food and Agriculture Organization (FAO, 2002) and World Bank (2002), reported that there is evidence that world wide food security has improved. They however, reported that the data are heavily skewed by success in certain regions and countries with large rural population such as China and India. This may be as a result of defective resource allocation and or management.

Olawoye (1997) reported that out of the 95\% small scale farmers who actually feed the nation, 55\% are women. According to Ajieko (1986), women accounted for half of the rural population and spent about two third of their time on food production activities. Despite these enormous contributions to economic development by women in most communities it is observable that there is gender imbalance when considering agricultural resource allocation. This has accounted for the impoverished status of rural women in Nigeria as noted by FAO (2002). This study therefore, was designed to study rural dwellers' perceptions of gender issues in agricultural resource management. In order to achieve this, the following questions were pertinent: what is the rural dweller understanding of the concept of gender? What gender issues are of interest in the study area? What constitute community resources which can generate issues in the communities and how are these resources accessed by rural people? 


\section{Methodology}

The study was carried out in Okpokwu Local Government Area of Benue State. According to National population Commission (NPC, 2006), Okpokwu has a population of 176,647 people. This was broken down to 91,563 males and 85,084 females and has about 28,000 farm families; it derives its name from River Okpokwu. It is about 170 kilometres away from Makurdi the state capital. It shares boundaries with Ohimini Local Government Area in the north, Ogbadibo in the west and Ado in the east. It is made up of three districts namely: Edumoga, Okpoga and Ichama which together has nineteen council wards:

The population for the study constitutes all gender categories, however, it is impracticable to include every body in the study sample, consequently, a group that cut across all major community stakeholders were identified and selected from each community because of their degree of homogeneity. Focus Group FGD was then used to elicit information for this study.

\section{Results and Discussions}

\subsection{Respondents Understanding of the Concept of Gender}

From the various group discussions, gender was generally (100\%) perceived as a concept referring to the biological differences between a man and woman, a contrast from the percept of IIRR (1998) that gender essentially refers to the social and economic differences between male and female. This position can lead to the invocation of cultural beliefs that may marginalize the female folks with respect resource allocation in the study area. This is because, in the study, the male is culturally/traditionally viewed as superior species, therefore, culture is consistently invoked to legitimize actions to their advantage (Ejembi, 2009).

\subsection{Some Gender Issues}

In order to clearly appreciate the effects of rural dwellers' perception on gender issues, some of the major gender issues in rural Nigeria were selected as part of the key questions during the FGD. They are as follows:

\subsubsection{Social responsibility}

Social responsibility relates to how individual members of the community are assigned roles in the society. This was included as an item for discussion because of the researcher's understanding that roles should be given to the most efficient, effective and conscientious persons. From the discussion however, the people agreed that they do not assign roles on the basis of competence. They explained that roles were clearly separated across cultural and biological lines, and that action that negates this cultural and natural provision was perceived as a taboo. This practice has the tendency to cause mismanagement of resources which ultimately will lead to high poverty status. Kinsgley Davies in explaining the theory of effective role allocation and performance, agreed that roles first of all most be filled, but by those best able to perform them, that the necessary training must be given to them and that these roles be performed conscientiously (Haralambos, Holbon and Healds, 2004). So if it is an agreed practice to allocate roles at all, then, the people concern should be able to identify those best able to 
perform it and this should not have any regard to the physical features of being a man or woman as is the case in the study area.

\subsubsection{Cultural provision}

Cultural provision is an abstract prescription for societal existence (Mandoza and Napoli, 1976). This is what stipulates expected behaviour from man, woman, children and any other member of the society such that if any of these people exhibit behaviour consistent with the cultural provision, it is applauded. It consequently, was featured as a check list during the discuss session. Some of the cultural provisions in the area were (i) all resource were communally owned, (ii) access was by inheritance and (iii) and male children were rightful heirs to community resources. It was agreed that these cultural provisions were defective and has consequently taken the society backwards by several steps. It was however difficult to accept that some of these provisions be modified for fear of the unknown. This fear negates the position of Mandoza and Napoli (1976), that human beings are older than culture for approximately two million years, and that it is possible for man to modify culture if he so wishes especially that culture is the machination of man but that man refused to do this because he has found it a veritable too for oppression of other human beings. He (man) will only be willing to change if such modifications are advantageous to him.

\subsubsection{Access to productive resources and benefits from the use of these resources}

Issues that border on cultural provision regarding access to productive resources and benefit accruing from the use of such resource were reviewed during the discussion session. It was revealed during the interaction that the male folk were usually given preference in terms of resource allocation. It is only in the event that there are no male members of the community that female members may reluctantly be allocated resources. This was said to be temporary as such allocations may be revoked in the event of the slightest indication of interest by a male member of the community. It was also explained that females were considered temporal members of the community as they were expected to get married and move to their husbands' homes.

The resultant effect of this practice is a perennial impoverishment of the female members of the communities, manifesting in their low socio-economic status, continuous discountenance of their contributions and persistent dependence on their male counterparts. This implies that the problem of poverty in the rural communities has persisted, because of the unequal access to productive resources. This finding corroborates that of van Allen (1976), that women's works were reduced into a socially subordinate part to that of their male counterparts, consequently, reducing their status from that of adult members of society into wards, wives and daughters, and social dependants. This is not a natural biological provision and thus should be reversed, especially that the practice is not taking the people to the 'promise land'.

\subsubsection{Decision making process}

This has to do with the day to day running of the social system. It is therefore important in the human interaction to determine who makes decisions: so, it constitutes one of the discussion items. The information collated show that decision for running the affairs of the community was an exclusive preserve of male members. The reason 
for excluding women from the decision making process was comprehensively agreed to be cultural. This may have adverse implication on women in terms of self development and confidence. People learn on the job or whatever assignment they are given in order to improve on them. It was pointed out by IIRR (1998) that women produce $60-80 \%$ of domestically produced food, provide more than half of the farm labour and shouldered $90 \%$ of the domestic responsibilities but get only $10 \%$ of the benefits of the total income from their labour. This may be because of their complete absence from the decision making equation.

\subsection{Community Resources and their Management Practices}

Considering the confusion associated with what should be regarded as community resources, the groups identified community resources as human beings, land (soil), water and forest. Management practices adopted for each of these resources to ensure their conservation were also discussed and the results presented in Table 1. However, only the natural resources were discussed. It is to be noted however, that human beings were ranked the most important community resource, apparently because, they are responsible for the management and coordination of the other resources.

Table 1. Distribution of responses according to their perception of community resources

\begin{tabular}{lcc}
\hline Perception as community resources & Frequency of responses* & Percentage \\
\hline Human beings & 109 & 34.71 \\
Water & 45 & 14.33 \\
Land & 89 & 28.34 \\
Forest & 71 & 22.61 \\
Total & 314 & $\mathbf{1 0 0}$ \\
\hline
\end{tabular}

* due to multiple responses

Table 2. Ranking of community resources by respondents

\begin{tabular}{lc}
\hline Resources & Ranking \\
\hline Human beings & 1 \\
Land & 2 \\
Water & 3 \\
Forest & 4 \\
\hline
\end{tabular}

\subsubsection{Land (soil)}

This refers to agricultural and arable land. They all agreed that land is communally owned but can be allocated to members of the community by the community heads that hold the land in trust or distributed to children by parents who already have their lands. Female children were not included in this distribution. Communal efforts are used to protect lands that have not yet been distributed to individuals from natural forces of destruction. They also indicated that they have laws against bush burning and indiscriminate hunting. These are usually done communally when necessary sacrifices have been carried out. If pieces of land allocated to individual were taken by outsiders, the community will mobilize itself to recover it. 


\subsubsection{Water}

All communities in Okpokwu live on natural water source like streams as they have not started benefiting from government aided water sources such as tube wells and boreholes. Some of the streams dry up during the dry season and consequently, require adequate strategy to conserve water from all season supply. The groups agreed that they harvest and store water during rainy season in pits which are dug and plastered for water storage. In the streams, men are meant to dig up the water ways so that water can spring and collect in these holes. Women then go to fetch with definite laws that must be adhered to. At this time, nobody will be allowed to take his or her bath around the vicinity to avoid water contamination.

\subsubsection{Forest}

Forest here refers to both natural and artificial forests. The natural forest constitutes timber and non timber trees. The natural timber forest helps them in their construction works, especially, in building of their houses and bridges. The non timber constitutes sources of fruits and other economic benefits. Women and children are assigned the responsibility of gathering non-timber produces for onward processing to the market. Usually, most men allow their women with the money realized from the sales of this produce to enable them cater for domestic needs. However, if what was realized was much, then the money or at least a good part of it was to be remitted to the husbands. These economic trees are normally protected from destruction by the men; they fire trace the vicinity and prevent undue abuse of forest resources.

\section{Conclusion}

From the analysis of the information gathered in this study, it is clear that there is male domination in the study area. It is important to note that in spite of this obvious domination, women have continued to play vital roles in the management of resources in the communities behind the scene. It is therefore, concluded that men enjoyed the benefits accruing from these resources most even though they do not contribute more than women due to cultural provisions. If women were to benefit as much, they will be able to recycle these resources to the extent that the impoverished state of the rural populace will be ameliorated.

\section{References}

African Development Bank (ADB). 2005. "Gender, Poverty and Environmental Indicators on African countries". Tunis, vol. vi 17-19.

Ajieko, M.A. 1986. "Integration of Women into Farming System". Research Extension for Faster Technological Change. Egerton University College Research Committee paper No 11 pp 1-5.

Ejembi, E. P., Omoregbee, F. E. and Ejembi, S. A. 2006. Farmers assessment of the training and visit extension system in central Nigeria: evidence from BarkinLadi, plateau state. J. Soc. Sci. 12(3):207-212.

Friestone, S. 1971. "The Dialectice of six. Bentan USA.

Food and Agriculture Organization (FAO). 2002. 'Dimitra Project-Rural Women and Development". Available online at: www.fao.org/sd/dimitra. 
Haralambos, M. Holborn, M and Heald, R. M. 2004. Sociology: Themes and Perspectives. New Delhi, India: Oxford University Press pp65-78.

International Institute for Rural Reconstruction (IIRR). 1998. "Sustainable Agriculture Extension Manual for Eastern and Southern African”. Majestic Printing works Ltd., Nairobi Kenya. Pp 70-82.

Mandoza, M.G. and Napoli, V. 1977. "Systems of sociology": An introduction to social science $2^{\text {nd }}$ edition. D.C. Health \& co. Canada 706p.

Olawoye, J.F. 2009. "Qualitative Techniques and Methodological Issues in the Study of Inequality and Poverty". A paper presented at the 1999 graduate studies capacity building programme organized by the centre for econometric and allied Research (CEAR). University of Ibadan, Nigeria

Pinstrup-Anderson, P., Rajil, P. L,and Mark, W.R.. 1999. "World Prospects: Critical Issues for early Twenty first century, International Food Policy research Institute, Washington, D.C. USA. Pp22-29.

Smith, L.C and Hadad I.J. 1999. "Explaining child malnutrition in Developing countries a cross country Analysis" Discussion paper. International Food Policy Research Institute (IFPRI). Washington, D.C.USA.

Van Allen, J. 1976. “Aba Riots of the Igbo Women's war?" In: Hafkin, N.J. and Bay, E.G. (ed). Women in Africa. Stanford University Press, USA pp.59-70.

World Bank. 2002. World Development Report (2000/2001): “Attacking Poverty. World Bank, Washington DC, USA, pp12-15. 